\title{
Nano-size layered manganese-calcium oxide as an efficient and biomimetic catalyst for water oxidation under acidic conditions: comparable to platinum $\dagger$
}

Received 29th November 2012,

Accepted 24th January 2013

DOI: $10.1039 / c 3 d t 32864 c$

www.rsc.org/dalton

\author{
Mohammad Mahdi Najafpour, ${ }^{* a, b}$ Kevin C. Leonard, ${ }_{1}^{\mathrm{C}}$ Fu-Ren F. Fan, ${ }^{\mathrm{C}}$ \\ Mahmoud Amouzadeh Tabrizi, ${ }^{a}$ Allen J. Bard, ${ }^{* c}$ Cecil K. King'ondu, ${ }^{\prime}$ Steven L. Suib, ${ }^{d, e}$ \\ Behzad Haghighi ${ }^{\mathrm{a}, \mathrm{b}}$ and Suleyman I. Allakhverdiev ${ }^{\mathrm{f}, \mathrm{g}}$
}

Inspired by Nature's catalyst, a nano-size layered manganese-calcium oxide showed a low overvoltage for water oxidation in acidic solutions, which is comparable to platinum.

\section{Introduction}

A strategy to store solar, wind, ocean current, tidal or wave energy is hydrogen production by water splitting as discussed by Bockris. ${ }^{1}$ The water oxidation half reaction in water splitting is overwhelmingly rate limiting and needs a high overpotential $(>1 \mathrm{~V})$ that results in low conversion efficiencies when working at the required current densities. ${ }^{1}$ At this high voltage, other chemicals could also get oxidized and this is environmentally unacceptable for large-scale $\mathrm{H}_{2}$ production. ${ }^{1}$ Thus, a significant challenge for a sustainable hydrogen economy is to design an efficient, stable, environmentally friendly and low cost water oxidation catalyst. ${ }^{2}$

While heavy metals are widely used as catalysts, organisms manage to use abundant, low cost and environmentally friendly transition metals for the same purpose.

Water oxidation in Nature is catalyzed by a $\mathrm{Mn}_{4} \mathrm{O}_{5} \mathrm{Ca}$ complex housed in a protein environment in photosystem II (PSII) that controls reaction coordinates, proton movement and water access. $^{3}$

\footnotetext{
${ }^{a}$ Department of Chemistry, Institute for Advanced Studies in Basic Sciences (IASBS), Zanjan, 45137-66731, Iran.E-mail: mmnajafpour@iasbs.ac.ir; Fax: (+98) 241415 3232; Tel: (+98) 2414153201

${ }^{b}$ Center of Climate Change and Global Warming, Institute for Advanced Studies in Basic Sciences (IASBS), Iran

${ }^{c}$ Center for Electrochemistry, Department of Chemistry and Biochemistry, The University of Texas at Austin, Austin, TX 78712-0165, USA.

E-mail: ajbard@mail.utexas.edu; Fax: (+7) 4967330 532; Tel: (+7) 4967731837

${ }^{d}$ Department of Chemistry, University of Connecticut, 55 N. Eagleville Rd., Unit 3060, Storrs, CT 06269-3060, USA

${ }^{e}$ Institute of Materials Science, University of Connecticut, Storrs, CT 06269, USA ${ }^{f}$ Controlled Photobiosynthesis Laboratory, Institute of Plant Physiology, Russian Academy of Sciences, Botanicheskaya Street 35, Moscow 127276, Russia

${ }^{g}$ Institute of Basic Biological Problems, Russian Academy of Sciences, Pushchino, Moscow Region 142290, Russia

$†$ Electronic supplementary information (ESI) available. See DOI: $10.1039 / \mathrm{c} 3 \mathrm{dt} 32864 \mathrm{c}$
}

Recently, the crystal structure of the manganese-calcium cluster of PSII at an atomic resolution was reported by Shen and his co-workers (Fig. 1a). ${ }^{4}$ In this structure metal ions, one calcium and four manganese ions, are bridged by five oxygen bridges (Fig. 1a). Four water molecules were also found in this structure of which two of them are suggested as the substrates for water oxidation. ${ }^{4}$ In the past few years, there has been a major research effort for the synthesis of various manganese complexes aimed at simulating the water oxidizing complex of PSII. ${ }^{5}$ However, no manganese complex has been discovered so far that is able to act as a homogeneous catalyst for water oxidation, ${ }^{6}$ although Shilov, Morita and Harriman introduced manganese oxides as catalysts for water oxidation. ${ }^{7}$ Recently, Najafpour et al., aimed at simulating the $\mathrm{Mn}_{4} \mathrm{O}_{5} \mathrm{Ca}$ cluster in PSII, introduced manganese-calcium oxides as efficient catalysts for water oxidation. ${ }^{8}$ These layered manganese-calcium oxides are very closely related to the water oxidizing cluster in PSII (Fig. 1b). ${ }^{8 e}$ Here, the layered manganese-calcium oxide powder shows electrocatalytic properties in strongly acidic solution. One of the problems with determining the catalytic activity of powders is that the electrode fabrication method can play a critical role in the overall performance of the material. In this study, we used two methods to measure the electrocatalytic activity for the oxygen evolution reaction (OER) of the layered manganese-calcium oxide powder; one where the catalyst was mixed with Nafion as a binder and a conductive carbon and cast onto an inert glassy carbon (GC) electrode, and a second where the catalytic activity of the powder was measured directly in a slurry without fabricating an electrode. For the direct measurement, i.e. without fabricating an electrode, the catalyst powder was suspended in the electrolyte and was stirred so that individual particles were continually in contact with the inert working electrode. If the working electrode has a high overpotential for the OER, as GC does, one can determine the catalytic properties of the powder and we show that these results are in good agreement with those with the fabricated electrode. 


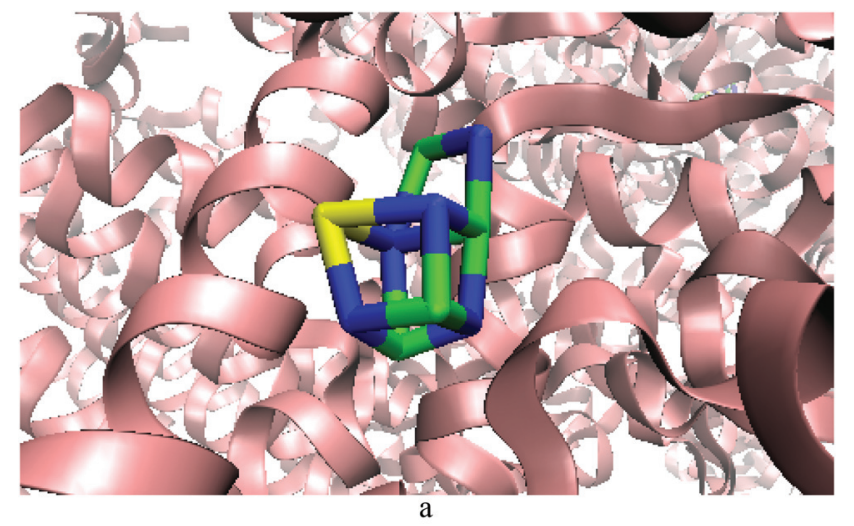

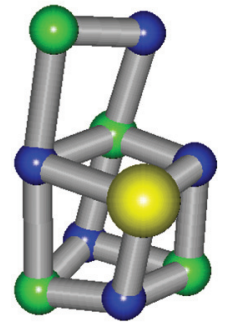

b

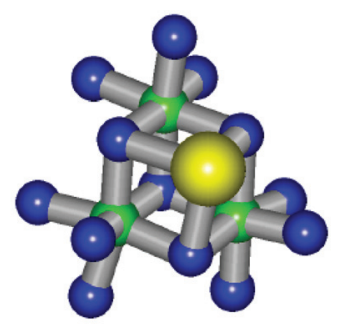

c
Fig. 1 The crystal structure of the manganese-calcium cluster and its amino acids around it at an atomic resolution (a). ${ }^{4}$ The manganese-calcium cluster of PSII (b). ${ }^{4}$ Motif of edge-sharing $\mathrm{MnO}_{6}$ octahedra (di- $\mu$-oxido bridging) in the manganese-calcium oxides ${ }^{8 e}$ (manganese: green, oxygen: blue, calcium: yellow, nitrogen: red, carbon: cyan) (c). Image (a) was made with VMD and is owned by the Theoretical and Computational Biophysics Group, NIH Resource for Macromolecular Modeling and Bioinformatics, at the Beckman Institute, University of Illinois at Urbana-Champaign. The original data are from ref. 4 (PDB: 3ARC).

\section{Materials and methods}

All reagents and solvents were purchased from commercial sources and were used without further purification. MIR spectra of $\mathrm{KBr}$ pellets of compounds were recorded on a Bruker vector 22 in the range between 400 and $4000 \mathrm{~cm}^{-1}$. TEM and SEM were carried out with a JEOL JEM 2010 Fas TEM operating at $200 \mathrm{kV}$ and LEO 1430VP, respectively. The X-ray powder patterns were recorded with a Bruker, D8 ADVANCE (Germany) diffractometer ( $\mathrm{Cu}-\mathrm{K} \alpha$ radiation). Manganese atomic absorption spectroscopy (AAS) was performed on an Atomic Absorption Spectrometer Varian Spectr AA 110. Prior to analysis, the oxides (10.0 mg metal) were added to $1 \mathrm{~mL}$ of concentrated nitric acid and $\mathrm{H}_{2} \mathrm{O}_{2}$, left at room temperature for at least $1 \mathrm{~h}$ to ensure that the oxides were completely dissolved. The solutions were then diluted to $25.0 \mathrm{~mL}$ and analyzed by AAS.

\section{Synthesis of compounds}

Different conditions were used to obtain the catalysts for water oxidation but the best catalyst was synthesized using the following conditions:

Solution 1: $\mathrm{CaCl}_{2} \cdot 4 \mathrm{H}_{2} \mathrm{O} \quad(2.70 \mathrm{mmol}, \quad 0.494 \mathrm{~g})$ and $\mathrm{Mn}\left(\mathrm{CH}_{3} \mathrm{COO}\right)_{2} \cdot 4 \mathrm{H}_{2} \mathrm{O}(5.6 \mathrm{mmol}, 1372 \mathrm{mg})$ were dissolved in water $(5 \mathrm{~mL})$. The mixture was stirred for about $10 \mathrm{~min}$ at room temperature.

Solution 2: to a solution of $\mathrm{KMnO}_{4}(2.4 \mathrm{mmol}, 379 \mathrm{mg})$ in $100 \mathrm{~mL}$ water, $\mathrm{KOH}(17.0 \mathrm{~g})$ was added to obtain a hot $\mathrm{KOH}-$ $\mathrm{KMnO}_{4}$ solution.

Addition of solution 1 to solution 2 under vigorous stirring resulted in a dark precipitate. Then the mixture was allowed to cool with continued stirring for $2 \mathrm{~h}$.

The obtained suspension was filtered and washed with distilled water $(3 \mathrm{~L})$ before being allowed to dry for $12 \mathrm{~h}$ at $60^{\circ} \mathrm{C}$ in an oven. Then the solid was heated to $400{ }^{\circ} \mathrm{C}$ for $10 \mathrm{~h}$ in air to obtain a brown powder. Yield: \%99; AAS: Mn (42.5\%) and Ca (4.9\%); IR $\left(\mathrm{cm}^{-1}\right): 3400(\mathrm{br}, \mathrm{O}-\mathrm{H})$, see Fig. S2. $†$ The oxide could be formulated as $\mathrm{Ca}_{0.16} \mathrm{MnO}_{2} \cdot 2 \mathrm{H}_{2} \mathrm{O}$.

\section{Electrode fabrication method}

In the first method, an electrode was fabricated by dropcasting the layered manganese-calcium oxide powder onto a GC electrode. To effectively coat the GC electrode, a suspension was made by combining $2.5 \mathrm{mg}$ of the catalytic powder, $0.88 \mathrm{mg}$ of conductive carbon (Vulcan), $125 \mu \mathrm{L}$ of $5 \mathrm{wt} \%$ Nafion solution (Sigma-Aldrich), and $625 \mu \mathrm{L}$ of deionized Milli-Q water. After sonicating this suspension for $\sim 15 \mathrm{~min}$ it was drop-cast onto a $3 \mathrm{~mm} \mathrm{GC}$ electrode (CH Instruments) by applying $40 \mu \mathrm{L}$ of the suspension onto the electrode and allowing it to air dry for over $12 \mathrm{~h}$.

The electrochemical measurements were performed in a specially designed borosilicate glass U-type cell in a 3-electrode configuration. The working electrode was a $3 \mathrm{~mm}$ GC disk electrode ( $\mathrm{CH}$ Instruments), the counter electrode was a Pt wire, and an $\mathrm{Ag} / \mathrm{AgCl}$ electrode was used as the reference. However, all experiments are reported potential $v s$. the reversible hydrogen electrode (RHE). The electrochemical characterization was done by linear sweep voltammetry using an Autolab PGSTAT128N potentiostat (Metrohm USA, Inc.) at a scan rate of $1 \mathrm{mV} \mathrm{s}^{-1}$. Comparisons of the catalytic activity for the OER were made between a bare GC electrode and a GC electrode coated with the layered manganese-calcium oxide. Each sequence of tests for the layered manganese-calcium oxide coated electrodes was repeated twice under 3 different electrolyte and $\mathrm{pH}$ conditions $\mathrm{pH}=1(0.1 \mathrm{M}$ trifluoroacetic acid (TFA)), $\mathrm{pH}=7$ (0.2 M phosphate buffer solution), and $\mathrm{pH}=14$ $(1 \mathrm{M} \mathrm{NaOH})$. The phosphate buffer solution was made by diluting a $1 \mathrm{M}$ stock solution, which was made by dissolving $4.97 \mathrm{~g}$ of $\mathrm{Na}_{2} \mathrm{HPO}_{4}$ with $1.93 \mathrm{~g}$ of $\mathrm{NaH}_{2} \mathrm{PO}_{4}$ in $50 \mathrm{~mL}$ of deionized Milli-Q water.

\section{Direct convective-suspension-collision technique}

In addition, the catalytic activity of the layered manganesecalcium oxide powder for the OER was also measured directly by a convective-suspension-collision technique. In this 
technique, which is a large-scale version of the technique used to look at single nanoparticles collisions, ${ }^{12}$ catalytic powders suspended in an electrolyte are continuously stirred such that they collide with a working electrode. Before measuring the catalytic activity of the powders, a background measurement was performed to determine the onset potential for oxygen evolution of a bare GC electrode. Prior to each experiment, the GC electrode was polished with $0.3 \mu \mathrm{m}$ alumina powder and subsequently washed with deionized Milli-Q water. Again, the electrochemical characterization was done by LSV using an Autolab PGSTAT128N potentiostat (Metrohm USA, Inc.) at a scan rate of $1 \mathrm{mV} \mathrm{s}^{-1}$ while stirring with a $\sim 1 \mathrm{~cm}$ magnetic stirrer bar at $600 \mathrm{rpm}$. Two complete forward and reverse scans were performed on the bare GC electrode, and the second forward scan from each batch is reported.

After performing LSV on the bare GC electrode, the test was repeated with the addition of the catalytic powders. Here, $2 \mathrm{mg}$ of the catalytic powder was added to $10 \mathrm{~mL}$ of the electrolyte in the center section of the U-type cell. The catalytic powderelectrolyte suspension was sonicated for $c a .15 \mathrm{~min}$ prior to electrochemical testing. Stirring at $600 \mathrm{rpm}$ allowed the powder to remain in suspension and make sufficient contact with the GC electrode. To determine the catalytic activity, the LSVs of the GC electrode both with and without the catalytic powder were compared. Each sequence of tests for the layered manganese-calcium oxide powder was repeated twice under 3 different electrolyte and $\mathrm{pH}$ conditions $\mathrm{pH}=1\left(0.1 \mathrm{M} \mathrm{HClO}_{4}\right)$, $\mathrm{pH}=7$ (0.2 M phosphate buffer solution), and $\mathrm{pH}=13(0.1 \mathrm{M}$ $\mathrm{KOH})$. In addition, LSV on a $2 \mathrm{~mm}$ Pt disk electrode $(\mathrm{CH}$ Instruments) in the absence of the catalytic powder was also performed for comparison in each of the electrolytes.

\section{Results and discussion}

The compound was easily synthesized by the reaction of potassium permanganate, manganese(II) acetate and calcium chloride in the presence of potassium hydroxide (ESI $\dagger$ ). The nanometer-size of the particles ensures that most of the active sites are at the surface where they behave as water oxidizing sites. In IR spectra of the compound, a broad band at $\sim 3200-3500 \mathrm{~cm}^{-1}$ related to antisymmetric and symmetric $\mathrm{O}-\mathrm{H}$ stretching and that at $\sim 1630 \mathrm{~cm}^{-1}$ related to $\mathrm{H}-\mathrm{O}-\mathrm{H}$ bending are observed (ESI $\dagger) .{ }^{10}$

Characteristic absorption peaks in $400-800 \mathrm{~cm}^{-1}$ are due to $\mathrm{Mn}-\mathrm{O}$ and $\mathrm{Ca}-\mathrm{O}$ vibration. ${ }^{10}$ The oxide was found to be amorphous as XRD data for the compound are of very poor resolution (Fig. 2). However, the peak near the $2.4 \AA$ spacing $(2 \theta \sim 38)$, observed in all octahedrally coordinated manganese oxide materials, was observed in XRD patterns of the compound. ${ }^{11}$ Recently, we investigated the structure of this compound using extended-range X-ray absorption spectroscopy (XAS) at the K-edges of both manganese and calcium. The XAS results reveal striking similarities between the synthetic oxide and the manganese-calcium cluster of PSII (Fig. 1). Two different calcium-containing motifs were identified. One of the

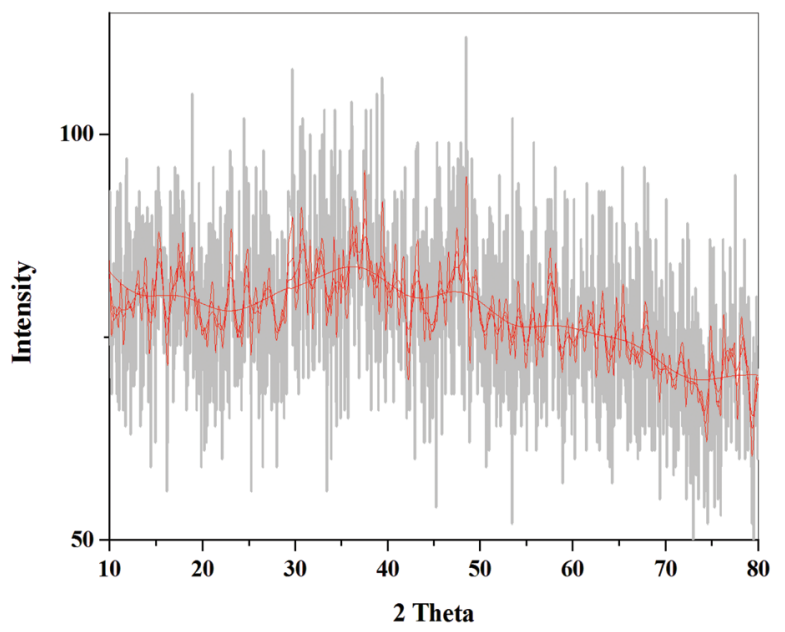

Fig. 2 XRD patterns of the obtained nano-sized manganese-calcium oxide (grey) and FFT Filter Smoothing ${ }^{9}$ of XRD patterns of the compound (red) after deleting XRD patterns of $\mathrm{CaCO}_{3}$ and $\mathrm{CaO}$ (in addition to the amorphous phase, a trace amount of $\mathrm{CaCO}_{3}$ and $\mathrm{CaO}$ could be detected in this compound).

motifs was the formation of $\mathrm{Mn}_{3} \mathrm{CaO}_{4}$ cubes, as also proposed for the natural paragon in PSII, while the other calcium ions probably interconnected oxide-layer fragments.

To characterize the morphology of the prepared compound, oxide was studied by scanning electron microscopy (SEM) and transmission electron microscopy (TEM). SEM images show that the compound consists of aggregates of fundamental nanoscale particles from 20 to $70 \mathrm{~nm}$ in size (Fig. 3). The TEM picture allowed us to determine that the compound consists of nano-sheets. The high concentration of potassium hydroxide was found to be very important in synthesis of this nanometersize compound.

Linear sweep voltammograms were generated for the layered manganese-calcium oxide coated GC electrode and a bare GC electrode in electrolytes of $\mathrm{pH}=1, \mathrm{pH}=7$, and $\mathrm{pH}=$ 14 (Fig. 4).

As shown in Fig. 4, pH strongly affects the relative oxygen evolution activity of the layered manganese-calcium oxide powder. The layered manganese-calcium oxide has the highest catalytic activity for oxygen evolution under acidic conditions. This is demonstrated by the significantly less positive onset potential in the LSVs shown in Fig. 4A. In the $\mathrm{pH}=7$ solution, the oxygen evolution activity of the layered manganesecalcium oxide powder became only slightly better than that of GC (Fig. 1B). The catalytic activity decreases further when the $\mathrm{pH}$ was increased to 14 , as demonstrated by the layered manganese-calcium oxide coated electrode having a lower activity for oxygen evolution than GC.

To check the stability of the layered manganese-calcium oxide-electrode, three consecutive LSV sweeps were performed on the coated electrode under acidic conditions (Fig. 5). Here we found that the first sweep of the layered manganesecalcium oxide coated electrode initially shows a higher catalytic activity for oxygen evolution than GC as also shown in Fig. 4A. However, as the potential becomes more positive, the 


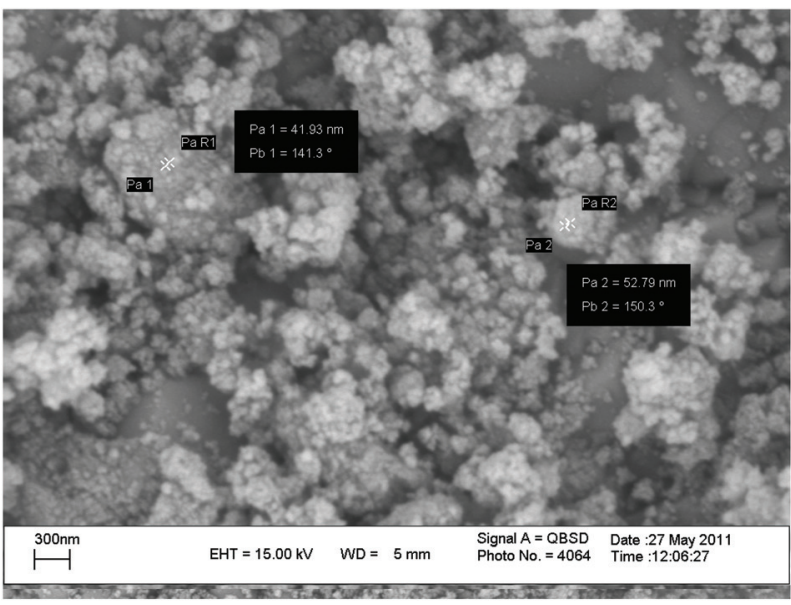

a

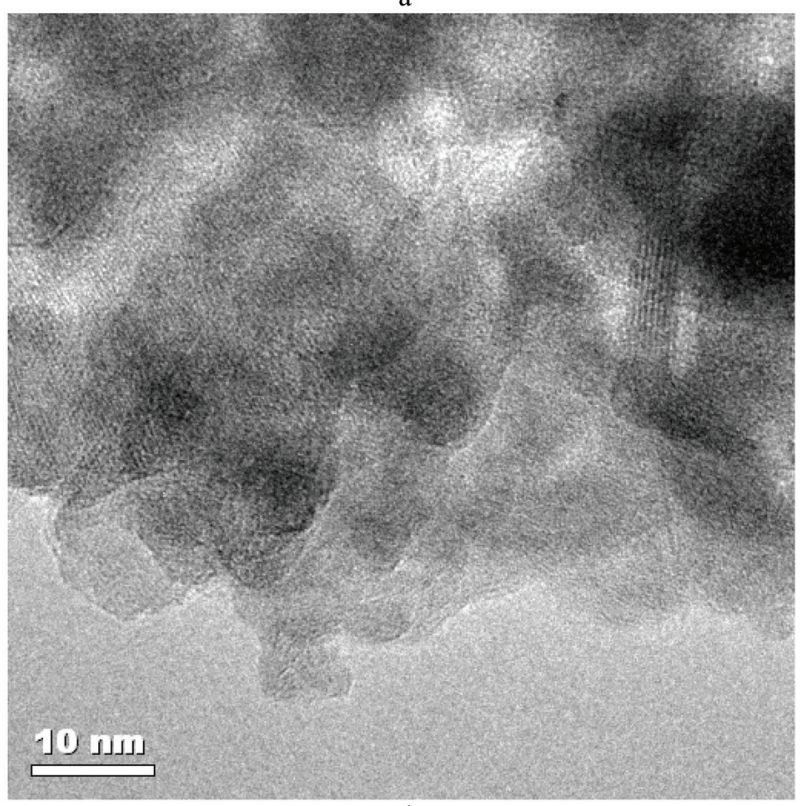

b

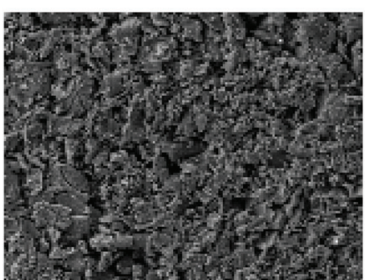

c

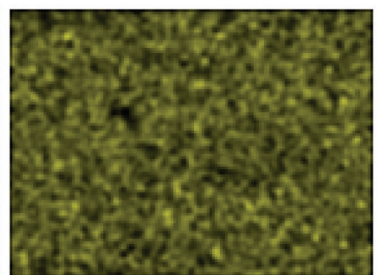

d

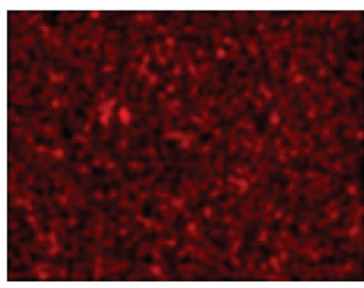

e

Fig. 3 SEM micrographs of nano-sized manganese calcium oxide (a). TEM images of nano-sized manganese calcium oxide (b). The SEM image of the catalyst (10 $\mu \mathrm{m}$ $\times 10 \mu \mathrm{m})(\mathrm{c})$ and EDX-Mapping of manganese (yellow) (d) and calcium (red) ions on its surface (e). The oxide could be formulated with $\mathrm{Ca}_{0.16} \mathrm{MnO}_{2} \cdot 2 \mathrm{H}_{2} \mathrm{O}$.
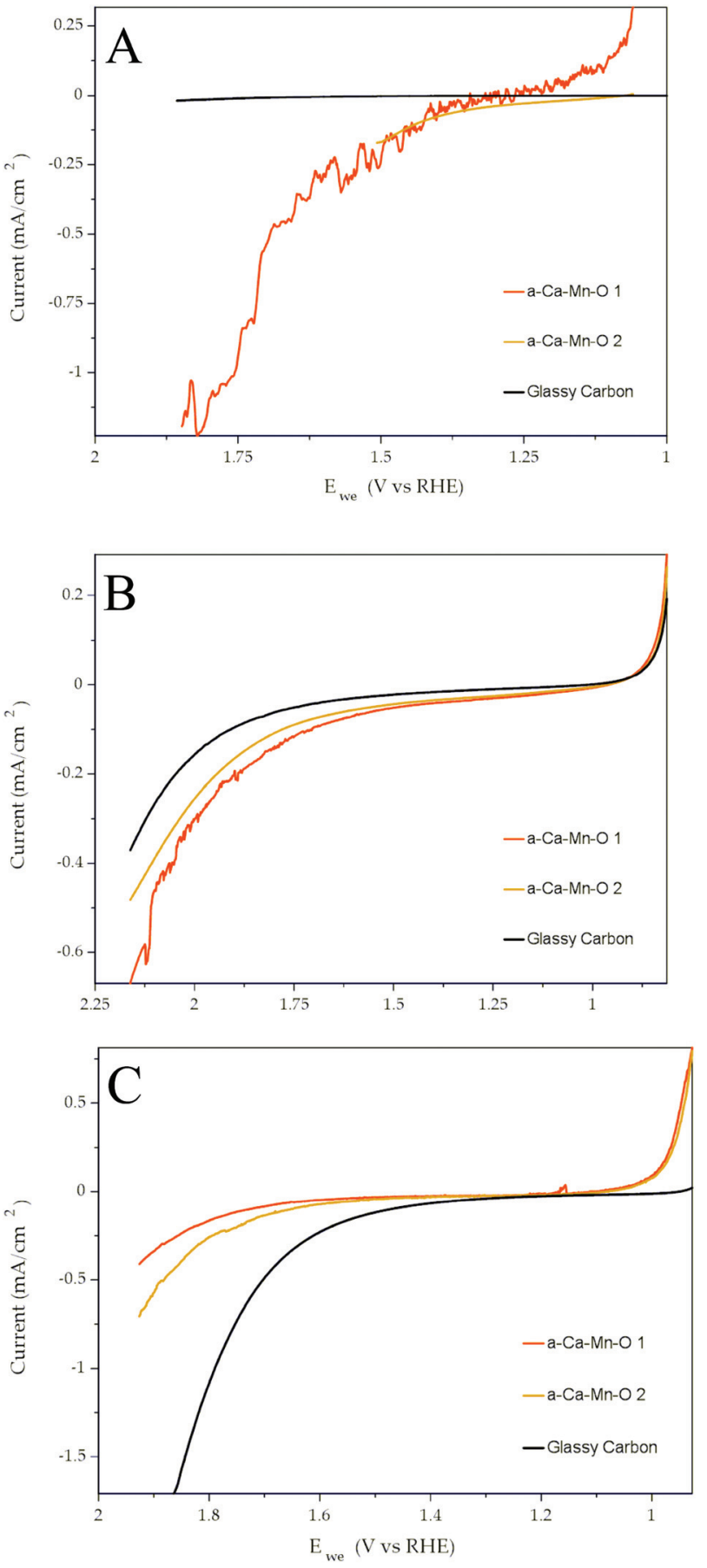

Fig. 4 Linear sweep voltammetry for the layered manganese-calcium oxide coated glassy carbon electrode along with a bare glassy carbon electrode at a scan rate of $1 \mathrm{mV} \mathrm{s}^{-1}$. (A) $0.2 \mathrm{M} \mathrm{TFA}-\mathrm{pH}=1$, (B) $0.2 \mathrm{M} \mathrm{PBS,} \mathrm{pH}=7$, (C) $1 \mathrm{M}$ $\mathrm{NaOH}, \mathrm{pH}=14$.

layered manganese-calcium oxide coated electrode begins to follow the LSV of GC. Subsequent sweeps of the layered manganese-calcium oxide coated electrode showed a decrease in catalytic activity until eventually, the LSVs were indistinguishable from the bare GC electrode. This demonstrated the difficulty in creating electrodes from catalytic powders because this decrease in activity could be due to deactivation of the 


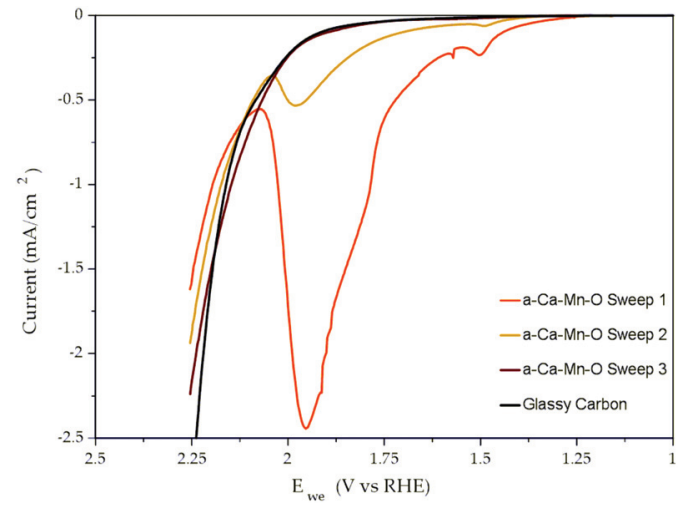

Fig. 5 Linear sweep voltammetry for the layered manganese-calcium oxide coated glassy carbon electrode along with a bare glassy carbon electrode in $0.1 \mathrm{M} \mathrm{HClO}_{4}, \mathrm{pH}=1$, at a scan rate of $1 \mathrm{mV} \mathrm{s}^{-1}$. Three consecutive sweeps of the layered manganese-calcium oxide electrode are shown.

catalysts or, more likely loss of the catalysts from the GC support electrode during oxygen bubble formation.

To characterize the catalytic powders without the need to fabricate electrodes, LSV was performed using the convectivesuspension-collision technique in three different electrolytes (as in Fig. 4) - $0.1 \mathrm{M} \mathrm{HClO}_{4}(\mathrm{pH}=1), 0.2 \mathrm{M} \mathrm{PBS}(\mathrm{pH}=7)$ and $0.1 \mathrm{M} \mathrm{KOH}(\mathrm{pH}=13)$. Again as with the coated electrodes shown in Fig. 4, there is a strong $\mathrm{pH}$ dependence on the catalytic activity of the layered manganese-calcium oxide powder. It showed the highest activity under acidic conditions, which is comparable to the catalytic activity for oxygen evolution on Pt (Fig. 6). In the 0.2 M PBS and 0.1 M KOH solutions, the oxygen evolution activity of the layered manganese-calcium oxide powder was only slightly higher than that of GC and lower than that of Pt (Fig. 6B,C). This $\mathrm{pH}$ trend for the convective-suspension-collision technique matches well with the technique in which the layered manganese-calcium oxide powder was cast onto the electrode.

The oxygen evolution reaction is a four-electron-transfer inner-sphere reaction with a complex mechanism. Thus, to quantify the kinetics for the samples tested using the convective-suspension-collision technique in acidic solution, the experimental data were fit to the Butler-Volmer relation assuming total irreversibility and no mass-transfer effects as shown in eqn (1),

$$
i=i_{0} \mathrm{e}^{(1-\alpha) f^{*} \eta}
$$

where $f$ is $F / R T$, and $\eta$ is the overpotential defined as $E-E^{0}$ which in our case is $E-(1.23-0.059 \mathrm{pH}) \mathrm{V}$. Using a best-fit approach, the exchange current density, $i_{0}$, and the transfer coefficient, $\alpha$, were determined for GC, Pt, and the layered manganese-calcium oxide.

The experimental results along with the best-fit curves from eqn (1) are shown in Fig. 7. The average values of the two experimental results for the GC and the layered manganesecalcium oxide experiments were used to determine $i_{0}$ and $\alpha$. In addition, the solution resistance, $R_{\mathrm{S}}$, was measured for each test and the $\mathrm{i} R_{\mathrm{s}}$ drop was subtracted from the experimental
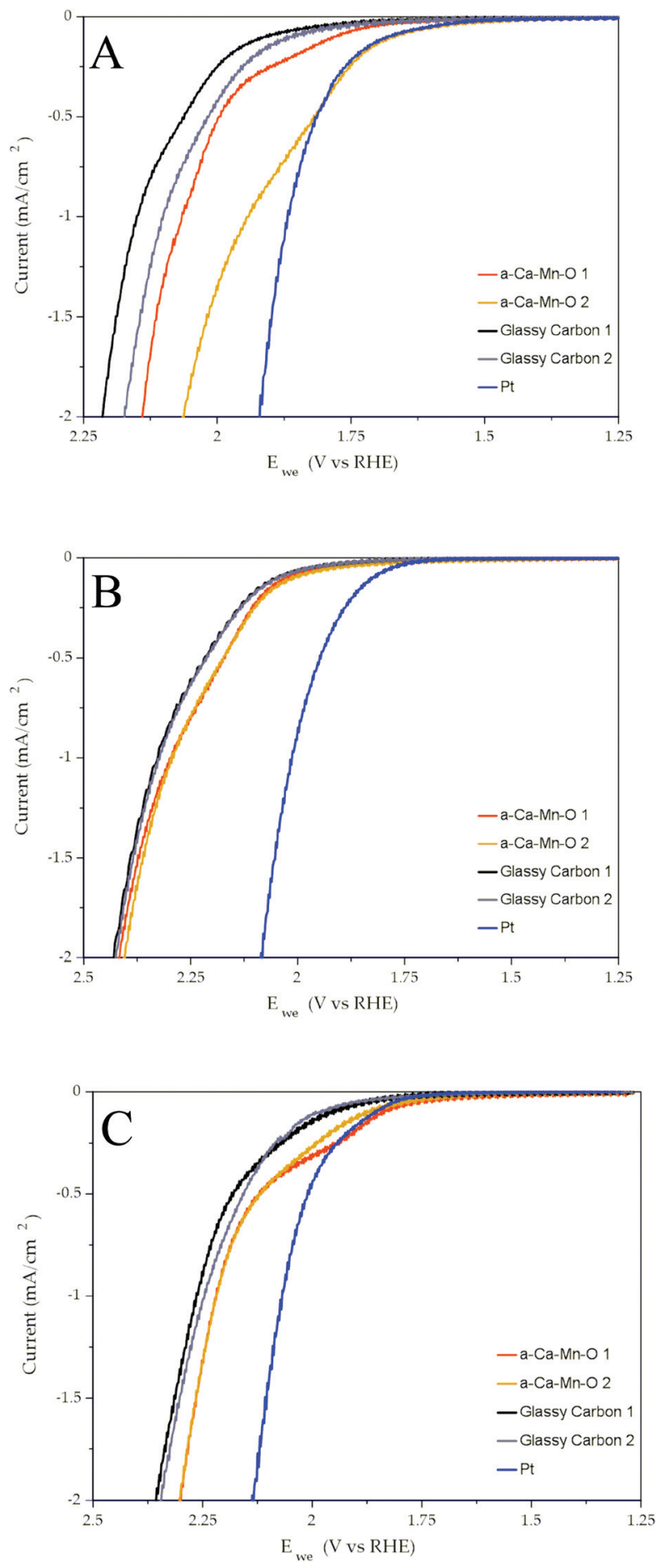

Fig. 6 Linear sweep voltammetry using a direct convective-suspension-collision technique of the layered manganese-calcium oxide powder along with comparisons of bare glassy carbon and $\mathrm{Pt}$ at a scan rate of $1 \mathrm{mV} \mathrm{s}^{-1}$ in (A) $0.1 \mathrm{M}$ $\mathrm{HClO}_{4}-\mathrm{pH}=1$, (B) $0.2 \mathrm{M} \mathrm{PBS}, \mathrm{pH}=7$, (C) $0.1 \mathrm{M} \mathrm{KOH}-\mathrm{pH}=13$.

data. From the simulations, we determined the values of $i_{0}$ and $\alpha$ for oxygen evolution on GC to be $-4.50 \times 10^{-8} \mathrm{~A} \mathrm{~cm}^{-2}$ and 0.69 , respectively. The exchange current density for Pt was over one order of magnitude higher at $-5.13 \times 10^{-7} \mathrm{~A} \mathrm{~cm}^{-2}$, with a similar value of $\alpha, 0.69$. The exchange current density 


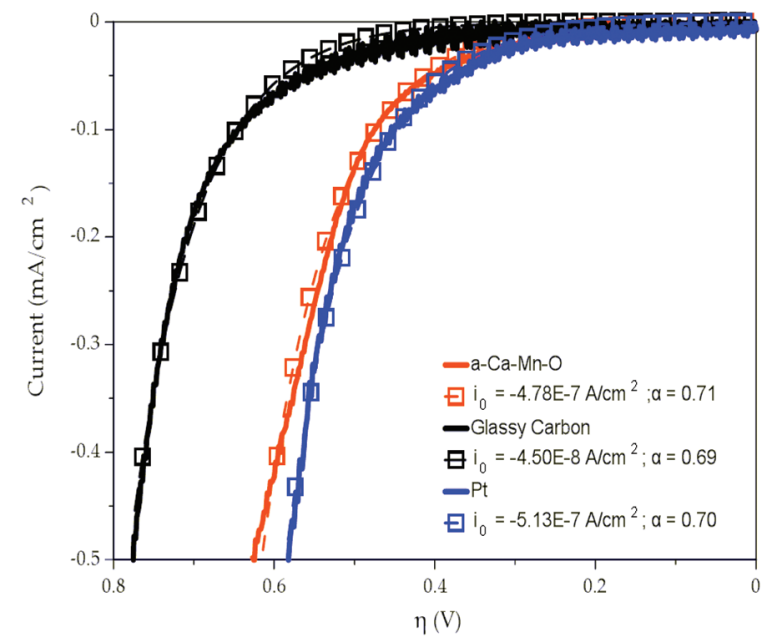

Fig. 7 Average of the two linear sweep voltammograms with iR correction using a direct convective-suspension-collision technique for the layered manganese-calcium oxide powder along with bare glassy carbon and Pt at a scan rate of $1 \mathrm{mV} \mathrm{s}^{-1}$ in $0.1 \mathrm{M} \mathrm{HClO}_{4}-\mathrm{pH}=1$. Also shown are Butler-Volmer best-fits assuming irreversibility and no mass transfer effects for the layered manganesecalcium oxide experiment ( $i_{0}=-4.78 \times 10^{-7} \mathrm{~A} \mathrm{~cm}^{-2}, \alpha=0.71$ ), glassy carbon $\left(i_{0}=-4.50 \times 10^{-8} \mathrm{~A} \mathrm{~cm}^{-2}, \alpha=0.69\right)$, and Pt $\left(i_{0}=-5.13 \times 10^{-7} \mathrm{~A} \mathrm{~cm}^{-2}, \alpha=0.70\right)$.

for the layered manganese-calcium oxide powder was also about one order of magnitude higher than that of bare GC at $4.78 \times 10^{-7} \mathrm{~A} \mathrm{~cm}^{-2}$, and only slightly lower than what was measured with Pt. The layered manganese-calcium oxide powder also had a similar transfer coefficient to the other two samples at 0.71 .

The assignment of the measured faradaic current to the OER is based on that reaction being the most probable oxidation under the experimental conditions. Alternatives would be catalyzed GC oxidation or Mn(II) oxidation. However experiments are being carried out using scanning electrochemical microscopy (SECM) that will be reported separately, in which oxygen generated at a catalyzed GC substrate is measured at the tip to obtain a quantitative evaluation of the current efficiency for oxygen evolution.

\section{The stability of the catalyst}

Hundreds of amino acids are around the manganese-calcium cluster in PSII. ${ }^{4}$ However, only a small fraction of the residues come in direct contact with the manganese-calcium cluster, and few of them are directly involved in catalysis. Roles for the residues that come in contact directly with the manganesecalcium cluster could be regulation of charges and electrochemistry of the manganese-calcium cluster, help in coordinating water molecules at appropriate metal sites, and in the stability of this cluster. For the manganese-calcium electrocatalyst used here, after treatment for $24 \mathrm{~h}$ with $\mathrm{Ce}(\mathrm{rv})(0.1 \mathrm{M}$, both oxidant and acidic solution, $\mathrm{pH}=1), 5 \%$ manganese and $23 \%$ calcium were found to leak into solution. The amounts with treatment in only water are $0 \%$ and $11 \%$ for manganese and calcium, respectively (Table 1). It is important to note that
Table 1 Amounts of dissolved calcium and manganese found by AAS in solution after exposure of the oxides to oxidation agents for $24 \mathrm{~h}\left(\left[\mathrm{H}_{2} \mathrm{O}_{2}\right]=4.4 \mathrm{mM}\right.$, $\left[\mathrm{HSO}_{5}{ }^{-}\right]=7.4 \mathrm{mM},[\mathrm{Ce}(\mathrm{IV})]=0.1 \mathrm{M}$ and $\left[\mathrm{Ru}(\mathrm{bpy})_{3}\right]^{2+}=0.5 \mathrm{mM} /\left[\mathrm{Co}\left(\mathrm{NH}_{3}\right)_{5} \mathrm{Cl}\right]^{2+}=$ $10.0 \mathrm{mM}))$ in acidic solutions

\begin{tabular}{llllll}
\hline & $\mathrm{H}_{2} \mathrm{O}_{2}$ & $\mathrm{Ru}(\mathrm{bpy})_{3}{ }^{2+}$ & $\mathrm{HSO}_{5}{ }^{-}$ & $\mathrm{H}_{2} \mathrm{O}$ & $\mathrm{Ce}(\mathrm{Iv})$ \\
\hline Dissolved manganese \% total & 0.25 & 1.46 & 0.23 & 0 & 5.00 \\
Dissolved calcium \% total & 86 & 90 & 31.22 & 11.00 & 23.00
\end{tabular}

the layered structure of these compounds shows no changes at the end of reactions but redox-inert ions in the structure may be replaced by other cations in solution (for example Ce(III), $\mathrm{K}(\mathrm{I}), \mathrm{Na}(\mathrm{I}), \mathrm{H}_{3} \mathrm{O}^{+}$and so on). ${ }^{8 a, 13}$

However, for some layered manganese oxides, we observe no special effect of the redox-inert ions but generally a redoxinert ion does increase the water oxidation activity of manganese oxide toward water oxidation. ${ }^{8,13}$

The efficiency of layered manganese oxides could be related to the open structure, small particle size and probably chemical changes of these oxides because of incorporation of redoxinert ions, in the structure. ${ }^{14}$ For example, Agapie et al. have reported a potential role for calcium in facilitating high oxidation states at a calcium-manganese multinuclear complex. ${ }^{15}$

In conclusion, the layered manganese-calcium oxide powder has relatively good kinetics for the oxygen evolution reaction under acidic conditions, but significantly slower under neutral and basic conditions. We verified these results using two different experimental techniques, one where the layered manganese-calcium oxide powder was cast onto a GC electrode and another where the catalytic activity was measured directly using a convective-suspension-collision technique.

\section{Acknowledgements}

MMN, MAT and BH are grateful to Institute for Advanced Studies in Basic Sciences and the National Elite Foundation for financial support. SLS and CK acknowledge the support of the US Department of Energy, Office of Basic Energy Sciences, Division of Chemical, Geochemical and Biological Sciences under grant DE-FG02-86ER13622.A000. KCL, FRF, and AJB acknowledge the support of the US Department of Energy, Office of Basic Energy Sciences, Division of Chemical, Geological and Biological Sciences through Grant DE-FG0209ER16119. This work was also supported by grants from the Russian Foundation for Basic Research (nos. 11-04-01389a, 12-0492101a and 13-04-92711a), Molecular and Cell Biology Programs of the Russian Academy of Sciences to SIA.

\section{Notes and references}

1 J. O. M. Bockris, Energy-the solar hydrogen alternative, Wiley \& Sons, New York, 1977.

2 W. Lubitz, E. J. Reijerse and J. Messinger, Energy Environ. Sci., 2008, 1, 15; A. F. Collings and C. Critchley, in Artificial 
Photosynthesis: from basic biology to industrial application, Wiley-VCH, 1st edn, 2005; M. M. Najafpour and Govindjee, Dalton Trans., 2011, 40, 9076; M. M. Najafpour, A. Nemati Moghaddam, S. I. Allakhverdiev and Govindjee, Biochim. Biophys. Acta, 2012, 1817, 1110; S. I. Allakhverdiev, V. Thavasi, V. D. Kreslavskib, S. K. Zharmukhamedov, V. V. Klimov, S. Ramakrishna, D. A. Los, M. Mimuro, H. Nishihara and R. Carpentier, J. Photochem. Photobiol., C, 2010, 11, 101; S. I. Allakhverdiev, J. J. Casal and T. Nagata, Photochem. Photobiol. Sci., 2009, 8, 137; S. Y. Reece, J. A. Hamel, K. Sung, T. D. Jarvi, A. J. Esswein, J. J. H. Pijpers and D. G. Nocera, Science, 2011, 334, 645; W. M. W. Kanan and D. G. Nocera, Science, 2008, 321, 1072; N. T. Hahn, H. Ye, D. W. Flaherty, A. J. Bard and C. B. Mullins, ACS Nano, 2010, 4, 1977; H. Ye, H. S. Park and A. J. Bard, J. Phys. Chem. C, 2011, 115, 12464; S. Hoang, S. Guo, N. T. Hahn, A. J. Bard and C. B. Mullins, Nano Lett., 2012, 12(1), 26; A. Minguzzi, F.-R. F. Fan, A. Vertova, S. Rondinini and A. J. Bard, Chem. Sci., 2012, 3(1), 217; A. J. Bard and M. A. Fox, Acc. Chem. Res., 1995, 28, 141; Q. X. Mi, A. Zhanaidarova, B. S. Brunschwig, H. B. Gray and N. S. Lewis, Energy Environ. Sci., 2012, 5, 5694; M. G. Walter, E. L. Warren, J. R. McKone, S. W. Boettcher, Q. X. Mi, E. A. Santori and N. S. Lewis, Chem. Rev., 2010, 110, 6446; J. E. Katz, T. R. Gingrich, E. A. Santori and N. S. Lewis, Energy Environ. Sci., 2009, 2, 103; A. Minguzzi, M. A. Alpuche-Aviles, J. R. López, S. Rondinini and A. J. Bard, Anal. Chem., 2008, 80, 4055.

3 G. Renger, Photosynth. Res., 2003, 76, 269; M. M. Najafpour, Plant Biosyst., 2006, 140(2), 163; M. M. Najafpour, Orig. Life Evol. Biosph., 2009, 39, 151; H. Chu, W. Hillier and R. J. Debus, Biochemistry, 2004, 43, 3152; G. Renger, J. Photochem. Photobiol., B, 2011, 104, 35; W. Hillier and T. Wydrzynski, Phys. Chem. Chem. Phys., 2004, 6, 4882; G. Renger and T. Renger, Photosynth. Res., 2008, 98, 53; M. M. Najafpour, A. Nemati Moghaddam, Y. N. Yang, E. Aro, R. Carpentier, J. J. Eaton-Rye, C. Lee and S. I. Allakhverdiev, Photosynth. Res., 2012, 114, 1.

4 Y. Umena, K. Kawakami, J. R. Shen and N. Kamiya, Nature, 2011, 473, 55.

5 W. Ruettinger and G. C. Dismukes, Chem. Rev., 1997, 97, 1; M. Yagi and M. Kaneko, Chem. Rev., 2001, 101, 21; C. W. Cady, R. H. Crabtree and G. W. Brudvig, Coord. Chem. Rev., 2008, 252, 444; B. Conlan, N. Cox, J. Su, W. Hillier, J. Messinger, W. Lubitz, P. L. Dutton and T. Wydrzynski, Biochim. Biophys. Acta, 2009, 1787, 1112; M. M. Najafpour and S. I. Allakhverdiev, Int. J. Hydrogen Energy, 2012, 37, 8753; M. M. Najafpour and V. McKee, Catal. Commun., 2010, 11, 1032; M. M. Najafpour, B. Kozlevcar, V. McKee, Z. Jaglicic and M. Jagodic, Inorg. Chem. Commun., 2011, 14 (1), 125; M. M. Najafpour, W. Hillier, A. N. Shamkhali, M. Amini, K. Beckmann, Z. Jagličić, M. Jagodic, P. Strauch, A. Nemati Moghaddam, G. Berettai and M. Bagherzadeh, Dalton Trans., 2012, 41, 12282.
6 K. Beckmann, H. Uchtenhagen, G. Berggren, M. F. Anderlund, A. Thapper, J. Messinger, S. Styring and P. Kurz, Energy Environ. Sci., 2008, 1, 668.

7 M. Morita, C. Iwakura and H. Tamura, Electrochim. Acta, 1979, 24, 357; S. Trasatti, J. Electroanal. Chem., 1980, 111, 125; A. Harriman, I. J. Pickering, J. M. Thomas and P. A. Christensen, J. Chem. Soc., Faraday Trans. 1, 1988, 84, 2795; V. Y. Shafirovich and A. E. Shilov, Kinet. Katal., 1979, 20, 1156; A. Iyer, J. Del-Pilar, C. K. King'ondu, E. Kissel, H. Fabian Garces, H. Huang, A. M. El-Sawy, P. K. Dutta and S. L. Suib, J. Phys. Chem. C, 2012, 116, 6474; M. M. Najafpour and A. Nemati Moghaddam, Dalton Trans., 2012, 41, 10292; Y. Gorlin and T. M. Jaramillo, J. Am. Chem. Soc., 2010, 132(39), 13612.

8 (a) M. M. Najafpour, T. Ehrenberg, M. Wiechen and P. Kurz, Angew. Chem., Int. Ed., 2010, 49, 2233; (b) M. M. Najafpour, J. Photochem. Photobiol., B, 2011, 104, 111; (c) M. M. Najafpour, Orig. Life Evol. Biosph., 2011, 41, 237; (d) M. M. Najafpour, Dalton Trans., 2011, 40, 3793; (e) I. Zaharieva, M. M. Najafpour, M. Wiechen, M. Haumann, P. Kurz and H. Dau, Energy Environ. Sci., 2011, 4, 2400; ( $f$ ) D. Shevela, S. Koroidov, M. M. Najafpour, J. Messinger and P. Kurz, Chem.-Eur. J., 2011, 17, 5415; (g) M. M. Najafpour, Orig. Life Evol. Biosph., 2011, 41, 237; (h) M. M. Najafpour, Geomicrobiol. J., 2011, 28, 714; M. M. Najafpour, M. Amouzadeh Tabrizi, B. Haghighi and Govindjee, Dalton Trans., 2012, 41, 3906; M. M. Najafpour, M. Amouzadeh Tabrizi, B. Haghighi and Govindjee, Dalton Trans., 2013, 42, 879; M. M. Najafpour, Chem. Commun., 2011, 47, 11724; M. M. Najafpour, J. Photochem. Photobiol., B, 2011, 104, 111; M. M. Najafpour, Orig. Life Evol. Biosph., 2011, 41, 237; M. M. Najafpour, F. Rahimi, E. Aro, C. Lee and S. I. Allakhverdiev, J. R. Soc. Interface, 2012, 9, 2383; M. M. Najafpour, D. Jafarian Sedigh, C. K. King'ondu and S. L. Suib, RSC Adv., 2012, 2, 11253; M. M. Najafpour and A. Nemati Moghaddam, New J. Chem., 2012, 36, 2514.

9 FFT Filter Smoothing is a signal processing technique typically used to remove noise from signals. For more information see: http://www.originlab.com/www/helponline/ Origin/en/Category/Smoothing.html

10 K. Nakamoto, in Infrared and Raman Spectra of Inorganic and Coordination Compounds, A Wiley-Interscience Publication, 6th edn, 2009.

11 H. Caot and S. L. Suib, J. Am. Chem. Soc., 1994, 116, 5334.

12 X. Xiao and A. J. Bard, J. Am. Chem. Soc., 2007, 129, 9610.

13 M. M. Najafpour, D. Jafarian Sedigh, B. Pashaeia and S. Nayeri, submitted manuscript.

14 M. M. Najafpour, B. Pashaei and S. Nayeri, Dalton Trans., 2012, 41, 7134; J. B. Gerken, J. Y. C. Chen, R. C. Mass, A. B. Powell and S. S. Stahl, Angew. Chem., Int. Ed., 2012, 124, 6780 .

15 J. S. Kanady, E. Y. Tsui, M. W. Day and T. Agapie, Science, 2011, 333, 733. 